\title{
PENGEMBANGAN BUKU BRAILLE STATISTIK DASAR PADA PROGRAM STUDI TEKNIK INFORMATIKA DI UNIVERSITAS PAMULANG
}

\section{DEVELOPING OF STATISTICS BRAILLE BOOKS BASE AT ENGINEERING INFORMATICS STUDY PROGRAM IN UNIVERSITY OF PAMULANG}

\author{
Nisak Ruwah Ibnatur Husnul* dan Lisda Fitriana Masitoh \\ 1) Pamulang University, South Tengerang \\ *dosen01267@unpam.ac.id
}

\begin{abstract}
Blind people who are not certified with inhibited intellectual rights have an education in inclusive schools. At present inclusive education in Indonesia has developed at the university level to facilitate students with visual impairment learning. In its journey, inclusive education in university encountered various obstacles. One of them is the difficulty of blind students in studying mathematics. Difficulties occur because screen readers used by blind students to understand files from lecturers cannot read mathematical equations or symbols. The purpose of this study is to produce a basic statistical Braille book to facilitate blind students to learn in inclusive classes with other students. This research is a research development with an adaptation of the development of the Borg \&amp; Gall development model which includes the stage of research and data collection, planning, initial product development, limited trials, product revisions, field trials and the latest revisions. The research instruments used were validation sheets, observation sheets, interview guidelines and statistical tests. The results of this study have produced basic statistics braille books that are feasible to use because they meet valid, practical and effective criteria based on the results of field trials. Therefore, statistical braille books can be used as an alternative choice in helping blind students to learn basic statistics material, especially in the Engineering Information program.
\end{abstract}

Keywords: braille, development, statistics, visual impairment.

\begin{abstract}
ABSTRAK
Tunanetra yang tidak disertai dengan hambatan intelektual berhak mendapatkan pendidikan di sekolah inklusi. Saat ini pendidikan inklusi di Indonesia telah berkembang pada tingkat perguruan tinggi untuk memfalitiasi mahasiswa tunanetra belajar. Dalam perjalanannya pendidikan inklusi di perguruan tinggi menemui berbagai kendala. Salah satunya kesulitas mahasiswa tunenetra belajar matematika. Kesulitan terjadi karena pembaca layar yang digunakan mahasiswa tunanetra untuk memahami file dari dosen tidak bisa membaca persamaan atau simbol matematika. Tujuan penelitian ini adalah untuk menghasilkan buku braille statistika dasar untuk memfasilitasi mahasiswa tunanetra belajar di kelas inklusi bersama dengan mahasiswa lainnya. Penelitian ini merupakan penelitian pengembangan dengan adaptasi pengembangan model pengembangan Borg \& Gall yang meliputi tahap penelitian dan pengumpulan data, perencanaan, pengembangan produk awal, uji coba terbatas, revisi produk, uji coba lapangan dan revisi akhir. Instrumen penelitian yang digunakan adalah lembar validasi, lembar observasi, pedoman wawancara
\end{abstract}


dan tes statistika. Hasil dari penelitian ini telah menghasilkan buku braille statistika dasar yang layak digunakan karena memenuhi kriteria valid, praktis dan efektif berdasarkan hasil uji coba lapangan. Oleh karena itu buku braille statistika dasar dapat digunakan sebagai pilihan alternatif dalam membantu mahasiswa tunanetra belajar materi statistika dasar, khususnya di program studi Teknik informatika.

\section{Kata kunci: braille, pengembangan, statistika, tunanetra.}

\section{PENDAHULUAN}

Istilah berkebutuhan khusus dalam percakapan sehari-hari dikonotasikan sebagai suatu kondisi yang menyimpang dari rata-rata umumnya (Mohammad Efendi, 2006). Penyimpangan yang dimaksud memiliki nilai lebih atau kurang. Pada pendidikan khusus atau pendidikan luar biasa, istilah menyimpang ditujukan kepada anak yang memiliki penyimpangan dalam hal fisik maupun mental dikarenakan ada permasalahan dalam kemampuan penglihatan, pendengaran, sosialisasi, berpikir, dan bergerak. Begitu juga pada anak yang berada di level perguruan tinggi. Anak-anak yang berasal dari pendidikan khusus atau pendidikan luar biasa perlu melanjutkan sekolahnya ke jenjang yang lebih tinggi. Akan tetapi sebagian besar mereka belum bisa merasakan pendidikan tinggi.

Setiap warga negara berhak untuk mendapatkan pendidikan, tidak terkecuali mereka yang memiliki kebutuhan khusus. Pendidikan harus dapat dinikmati oleh setiap orang. Pemerintah tentu saja menyadari bahwa terdapat banyak tantangan dalam menciptakan pendidikan yang dapat dinikmati oleh setiap orang, oleh karena itu pendidikan harus mampu menciptakan suasana yang non diskriminatif, memperhatikan hak setiap anak untuk berkembang, pencapaian tujuan, dan menghargai pendapat setiap anak. Salah satu usaha pemerintah dalam pemerataan pendidikan tinggi terhadap orang berkebutuhan khusus yaitu melalui pendidikan inklusif.

Pendidikan Inklusif merupakan sistem layanan pendidikan yang mengatur agar difabel dapat dilayani di sekolah terdekat, di kelas reguler bersama-sama teman seusianya. Tanpa harus dikhususkan kelasnya, siswa dapat belajar bersama dengan aksesibilitas yang mendukung untuk semua siswa tanpa terkecuali difabel. Inklusif merupakan respons untuk menanggapi kebutuhan anak dalam berkembang dan mencapai tujuan pembelajaran. Pendidikan inklusif diarahkan untuk dapat menyajikan proses pembelajaran dalam setting formal dan informal. Pendidikan inklusif diberikan dengan tujuan agar semua mahasiswa nyaman dan tidak merasakan adanya perbedaan antara anak berkebutuhan khusus dan anak pada umumnya. 
Perbedaan yang ada bukan lagi sebagai penghalang dalam belajar, namun menjadi tantangan. Pendidikan inklusif adalah cara yang efektif untuk mengurangi sikap diskriminatif, membuat masyarakat terbuka, membangun masyarakat inklusif, dan membuka kessatuan pendidikan untuk semua, untuk menyiapkan pendidikan yang efektif pada semua siswa dan meningkatkan efisiensi biaya masuk sekolah (UNESCO, 2003). Keberhasilan pendidikan inklusif dapat dilihat dari index for inclusion (Ainscow, 2005). Indeks inklusi mencakup pada dimensi budaya (creating inclusive cultures), dimensi kebijakan (producing inclusive policies), dan dimensi praktik (evolving inclusive practices). Pendidikan inklusif harus memperhatikan aspek budaya, kebijakan dan praktik dalam proses pembelajaran. Mengacu pada indeks inklusi, maka dapat disimpulkan bahwa pendidikan inklusif adalah pendidikan yang mampu mengakomodasi seluruh kebutuhan peserta didik baik dalam keragaman fisik, kecerdasan, social, emosional, dan kendalakendala lain yang mungkin muncul dalam proses pembelajaran sehingga mahasiswa dapat berkembang, memiliki kessatuan perpartisipasi, dan dapat mencapai tujuan bersamasama.

Salah satu karakter siswa dalam Pendidikan inklusi adalaha tunanetra.Tuna netra adalah orang yang memiliki kelainan fungsi penglihatan yang lebih tinggi yaitu tidak bisa atau kesulitan secara signifikan untuk membaca tulisan atau ilustrasi awas meskipun menggunakan alat bantu penglihatan (Nakata, 2003). Tunanetra punya kedaan psikologis dan social yang berbeda dengan orang berpenglihatan. Seorang tunanetra akan selalu menunggu aksi dari benda atau orang lain sebelum melakukan reaksi (Hidayat \& Suwandi, 2013). Pada setting Pendidikan tinggi, mahasiswa dengan gangguan penglihatan diklasifikasikan dalam tiga kategori menurut Herward (2017), yaitu buta total (totally blind), buta secara fungsional (functionally blind) dan anak dengan penglihatan lemah (low vision).

Beberapa perguruan tinggi yang membuka pendidikan inklusif yang memiliki mahasiswa tunanetra mengharuskan pengajar atau dosen untuk lebih memahami kebutuhan anak tunanetra tersebut. Pengalaman nyata merupakan salah satu kebutuhan yang harus dimiliki oleh mahasiswa tunanetra. Untuk menanamkan pengetahuan mahasiswa tunanetra tentang pengalaman konkrit disekelilingnya, dosen harus berusaha untuk memberikan pengalaman konkrit yang beranekaragam dan seluas-luasnya serta 
mengarahkan keterbatasan lingkup dan corak pengalaman mahasiswa tunanetra tersebut. Seperti halnya dalam proses perkuliahan di kelas.

Salah satu perguruan tinggi yang memiliki penyandang tunanetra adalah Universitas Pamulang. Berdasarkan hasil wawancara dengan dosen statistika dasar di Universitas Pamulang bahwa pada saat ini mahasiswa hanya diajarkan bagaimana memahami konsep dalam statistika. Menurut dosen statistika dasar semester dua Universitas Pamulang, para penyandang tunanetra dengan keterbatasan yang ada hanya membutuhkan statistika sebagai pelajaran yang harus mereka tempuh, bukan mata kuliah yang dapat menunjang profesi mereka. Jika mahasiswa tersebut mampu menjawab soal yang diberikan, maka mahasiswa tersebut sudah dianggap menguasai materi tersebut. Karena keterbatasan visual yang diderita mahasiswa tunanetra, akibatnya mereka sulit untuk mengikuti perkuliahan statistika dasar.

Statistika sebagai salah satu cabang dari matematika yang secara khusus mempelajari tentang data, menjadi salah satu cabang pembelajaran yang berkembang dan perlu dipelajari pemanfaatannya secara optimal (Irianto, 2003). Statistika sebagai bagian dari matematika memiliki peranan yang strategis dalam membentuk dan mengembangkan sikap serta pola pikir dari setiap manusia yang mengandalkan statistika dalam kesehariannya. Tak terkecuali bagi mahasiswa tunanetra yang nantinya memerlukan ilmu statistik dalam kehidupan keseharian mereka, serta digunakan pula pada saat penyusunan tugas akhir di kampus. Akan tetapi, mahasiswa tunanetra di Universitas Pamulang masih kurang tercukupi dengan fasilitas belajar yang seharusnya mereka dapatkan guna memudahkan mereka dalam mempelajari statistika.

Dalam proses perkuliahan, mahasiswa biasanya memperhatikan dan mencatat penjelasan dari dosen. Mahasiswa tunanetra juga melakukan hal yang sama seperti anak normal lainnya. Akan tetapi, mahasiswa tunanetra memiliki keterbatasan waktu untuk mencatat apa yang dijelaskan oleh dosennya. Sehingga tidak semua penjelasan dari dosennya bisa tercatat. Apalagi mata kuliah statistika yang dipenuhi dengan formula, mahasiswa tunanetra kesulitan untuk mengikuti perkuliahannya.

Salah satu fasilitas belajar untuk menunjang proses perkuliahan di kelas adalah bahan ajar. Prastowo (2011) mengatakan bahan ajar adalah segala sesuatu yang dapat digunakan untuk membantu guru atau dosen dalam melaksanakan kegiatan belajar mengajar. Pada pembelajaran statistika dasar inklusif, permasalahan yang sering muncul terkait 
bahan ajar adalah tidak adanya penyesuaian dengan kebutuhan mahasiswa tunanetra. Penyesuaian ini sangat penting karena dalam kelas inklusi terdapat beberapa mahasiswa yang mempunyai kelainan dan memerlukan layanan berbeda, termasuk pemberian bahan ajar yang digunakan. Bahan ajar perlu dipilih dengan tepat agar seoptimal mungkin membantu mahasiswa tunanetra dalam mencapai target pembelajaran yang sudah direncanakan.

Penelitian ini bermaksud membuat buku barille statistika untuk memfasilitasi kebutuhan mahasiswa tunanetra, karena sampai saat ini mahasiswa tunanetra belum terfasilitasi dengan bahan ajar yang bisa membantu dalam pembelajaran mereka. Terutama buku braille statistika yang didesain untuk kelas inklusi. Dengan adanya buku braille statistika tersebut diharapkan mahasiswa tunanetra mampu memaksimalkan diri dalam pembelajaran secara mandiri dan dapat menerima ilmu dengan baik dengan memanfaatkan buku tersebut.

Melalui pengembangan buku statistika dengan huruf braille ini, diharapkan dapat mengakomodasi kebutuhan mahasiswa tunanetra dalam memahami perkuliahan statistika dasar. Selain itu, para mahasiswa tunanetra juga dapat belajar secara mandiri. Untuk mempelajari statistika tidak cukup hanya sekali belajar saja, tetapi harus dilakukan secara berulang. Buku braille statistika yang bersifat portable, sehingga mahasiswa tunanetra tidak bergantung pada perkuliahan di kampus saja.

\section{METODOLOGI}

Penelitian ini termasuk dalam jenis research and development atau jenis penelitian dan pengembangan. Pengembangan dalam penelitian ini adalah pengembangan buku braille statistika dasar. Model pengembangan yang digunakan adalah model Borg \& Gall (1983) yang dimodifikasi dan disesuaikan dengan kebutuhan penelitian. Kualitas produk hasil pengembangan harus diujicoba untuk mengetahui kualitas produk pengembangan dari segi kevalidan, kepraktisan dan keektifan (Nieveen: 1999). Secara umum langkahlangkah dalam penelitian dan pengembangan yang digunakan adalah:

a. Penelitian dan Pengumpulan Data (Research and Information Collecting). Dalam tahap ini dilakukan survei awal untuk mengetahui urgensi dari penelitian. Selain itu juga dilakukan kajian teori serta penelitian-penelitian terdahulu untuk menguatkan rencana penelitian. 
b. Perencanaan (Planning). Merencanakan langkah-langkah penelitian pengembangan untuk menjamin keterlaksanaan penelitian.

c. Pengembangan Produk Awal (Develop Preliminary Form of Product). Dalam tahap ini dikembangkan berbagai instrumen penelitian. Draf produk pengembangan yang akan digunakan dalam uji coba terbatas harus melewati validasi dari ahli.

d. Uji Coba Terbatas (Preliminary Field Testing). Uji coba terbatas dilakukan untuk mengetahui kualitas produk dari segi kepraktisan.

e. Revisi Produk (Main Product Revision). Revisi produk dilakukan berdasarkan hasil uji coba terbatas atau uji coba keterbacaan.

f. Uji Coba Lapangan (Main Field Testing). Uji coba lapangan adalah ujicoba produk pengembangan pada kelas yang sesungguhkan untuk mengetahui kualitas produk pengembangan dari segi keefektifan.

g. Revisi Produk Akhir (Final Product Revision). Revisi produk akhir merupakan revisi produk berdasarkan temuan yang ada dilapangan.

Subjek uji coba produk pengembangan adalah satu mahasiswa tunanetra di program studi Teknik Informatika Universitas Pamulang. Penelitian ini melibatkan beberapa pihak diantarnya adalah dosen pengembang modul pembelajaran, validator, ahli braille dan dosen matematika.

\section{PEMBAHASAN}

\subsection{Pengembangan Produk Awal}

Modul statitika dasar yang digunakan oleh mahasiswa reguler menjadi dasar pengembangan buku braille statistika dasar di proram studi teknik informatika. Oleh karena itu sebelum mengembangkan buku braille, tim pengembang mengembangkan modul pembelajaran pada mata kuliah statistika dasar terlebih dahulu. Modul yang telah dikembangkan diberi masukan oleh beberapa ahli dalam bidang matematika untuk memastikan bahwa modul tersbut valid dan bsa digunakan untuk pengembaangan buku braille statistika dasar

Selanjutnya modul tersebut dibuat kedalam buku braille agar dapat digunakan mahasiswa tunanetra. Dalam proses pembuatan buku braille, tim peneliti bekerjasama dengan ahli braile. Beberapa kendala yang muncul dalam proses pengembangan buku braille adalah: 
a. Satu halaman buku teks yang diubah kedalam tulis braille akan menghasilkan lebih dari satu halaman braille. Hal ini membuat buku barille yang dikembangkan akan sangat tebal dan kurang praktis dibawa.

b. Beberapa simbol matematika belum diketahui lambang huruf braillenya. Masalah ini diselesaikan dengan salah satunya menggunakan symbol braille yang mendekati.

c. Rumus-rumus matematika yang singkat dalam tulisan awas, menjadi sangat panjang dalam penulisan braille sehingga perlu ketelitian dalam memastikan kebenaran penulisan rumus tersebut.

d. Rumus matematika bentuk equation yang dalam teks dapat dipahami mahasiswa dalam symbol standar tidak bisa diterapkan dalam teks braille. Penulisan braille selalu dari kanan ke kiri. Hal ini mengharuskan setiap rumus diberikan tanda tambahan agar mahasiswa tunanetra dapat memahaminya. Tanda tambahan tersebut misalnya adalah kurung siku, kurung kurawal dan lain-lain.

e. Penulisan braille yang membutuhkan area cukup luas atau lebar pada kertas, membuat beberapa tabel tidak bisa dituliskan sama persis dengan tabel di modul. Dengan demikian perlu modifikasi tertentu pada tabel-tabel tersebut. Hal ini membuat mahasiswa tunanetra harus lebih cermat dalam memahami tabel.

Dengan melewati proses ilmiah buku braille statistika dasar berhasil dikembangkan. Produk hasil pengembangan pada tahap ini disebut sebagai produk awal. Produk awal adalah buku braille statistika dasar yang telah memenuhi kriteria valid dan siap digunakan dalam uji coba di lapangan.

\subsection{Uji Coba Terbatas}

Uji coba terbatas dilakukan dengan cara mengimplementasikan pembelajaran di kelas dengan buku braille yang dikembangkan. Dari cakupan materi yang dikembangkan dipilih materi tertentu. Uji coba terbatas dilakukan untuk mengetahui bagaimana keterbacaan dari produk yang dikembangkan. Dalam ujicoba terbatas dilibatkan satu mahasiswa tunanetra semester lima. Mereka diminta mempelajari materi dalam buku. Setelah itu dosen memberikan pertanyaan-pertanyaan untuk menguji sejauh mana pemahaman mahasiswa dalam memahami materi yang ada di buku. Dari hasil ujicba terbatas diperoleh hasil bahwa mahasiswa terbantu dalam memahami rumus matematika yang sebelumnya tidak bias dipahamia oleh mereka. 
Temuan lain dalam ujicboba terbatas adalah diketahui bahwa ada perbedaan pembacaan tabel oleh mahasiwa tunanetra dengan mahasiswa berpenglihan ketika mempelajari materi yang berhubungan dengan SPSS. Pada umumnya ketika mempelajari SPSS, akan ada output hasil yang ditampilkan dalam tebel-tebal. Dengan bantuan pembaca layer mahasiswa dapat mengetahui informasi dalam tabel dengan memindahkan terlebih dahulu table ke file word. Akan tetapi jumlah kolom dan baris yang terbaca lebih banyak dari pada yang "terlihat" oleh mahasiswa berpenglihatan. Temuan ini dicatat dan dijadikan bahan revisi produk pengembangan.

\subsection{Revisi Produk}

Revisi produk dilakukan agar buku braille yang dikembangkan dapat lebih disempurnakan sebelum digunakan pada ujicoba lapangan. Point penting dalam revisi produk adalah merevisi uraina materi yang membingungkan bagi mahasiswa, menyederhanakan atau mengganti kalimat penjelasan yang membuat mahasiswa sulit memahami materi dan memberikan keterangan pada beberapa tabel yang ada dalam buku

\subsection{Uji Coba Lapangan}

Ujicoba lapangan dilaksanakan pada pembelajaran real di kelas. Uji coba dilakukan pada mata kuliah statistika dasar dipelajari di program studi Teknik informatika dalam 6 kali pertemuan. Untuk pembelajaran di kelas mahasiswa menggunakan buku braille dan bantuan program exel untuk membantu perhitungan. Uji coba lapangan melibatkan satu mahasiswa tunanetra semester lima dan seorang dosen matematika program studi Teknik informatika Universitas Pamulang.

\subsection{Revisi Akhir Produk}

Revisi akhir produk dilakukan berdasarkan temuan yang diperoleh dari proses uji coba lapangan. Tidak revisi yang terlalu signifikan. Hanya ada beberapa symbol braille yang salah ketik sehingga harus diperbaiki.

\subsection{Kefektifan Produk Pengembangan}

Kriteria keefektifan pembelajaran dengan buku braille statistika dasar ditetapkan terlebih dahulu oleh peneliti. Buku braille yang dikembangkan dikatakan efektif jika mahasiswa tunanetra dikelas inklusi sebagai subjek uji coba memperoleh nilai lebih dari 70 dalam tes yang diberikan. Sebelum dilakukan pembelajaran real, mahasiswa diberikan pretest untuk mengetahui kemampuan awal mahasiswa pada materi statistika dasar. Selain itu pretest dilakukan untuk memastikan, bahwa ketika ada perubahan tingkat pemahaman 
mahasiswa, maka hal itu berasal dari proses pembelajaan di kelas yang menggunakan buku braille matematika.

Berdasarkan hasil uji coba lapangan diperoleh hasil pretest mahasiswa adalah 35 . Setelah mengikuti pembelajaran dengan buku braille statistika dasar yang dikembangkan, mahasiswa diberi postest dan mendapatkan skor 78. Hasil ini menunjukkan bahwa produk pengembangan efektif ditinjau dari hasil belajar atau prestasi belajar mahasiwa.

\section{SIMPULAN}

Berdasarkan hasil pengembangan buku braille statistika dasar, analisis dan pembahasan yang dilakukan maka dapat disimpulkan bahwa buku braille statistika dasar yang dikembangkan layak digunakan. Kelayakan ini dikarenakan buku telah memenuhi kriteria valid, praktis dan efektif ditinjau dari hasil belajar mahasiswa. Oleh karena itu buku braille statistika dasar dapat digunakan sebagai pilihan alternatif dalam membantu mahasiswa tunanetra belajar materi statistika dasar, khususnya di program studi Teknik informatika.

\section{DAFTAR PUSTAKA}

Ainscow, M. 2005. Understanding The Development Of Inclusive Education System. Journal Of Research In Educational Psychology. Vol 3, 5-20.

Borg, W. R., \& Gall, M. D. 1983. Educational research an introduction. New York, NY: Longman. Herward, W.L. 2017. Exceptional Children: An Introductory Survey Of Special Education (3 edition). London: Merril Publishing Company.

Herward, W.L. 2017. Exceptional Children: An Introductory Survey Of Special Education (3 edition). London: Merril Publishing Company.

Hidayat, Asep AS dan Ate Suwandi. 2013. Pendidikan Anak Berkebutuhan Khusus Tunanetra Peserta Didik dengan Hambatan Penglihatan (Perspektif Pendidikan \& Layanan). Jakarta: Luxima Metro Media

Irianto, A. 2003. Statistika: Konsep dasar dan Aplikasinya. Jakarta: Kencana Prenada Media

Prastowo. 2011. Panduan Kreatif Membuat Bahan ajar Inovatif, Yogyakarta: Diva Press

Mohammad, E. 2006. Pengantar Psikopedagogik Anak Berkelainan. Jakarta: Bumi Aksara. 
Unesco. 2003. Overcoming Exclusion Through Inclusive Approaches in Education. A Challenge and Vision. Conceptual Paper.

Nakata, H. 2003. Educational Cooperation Bases System Construction Project, Implementation Report, Center for Research on International Cooperation in Educational Development (CRICED), University of Tsukuba, Japan.

Nieveen, N. 1999. Prototyping to reach product quality. Dalam J.V. den Aker, et al. Design approaches and tools in education and training. (pp. 125-136). London: ICO Cluwer Academic Publisher. 